\title{
The Relationship Between Body Weight and Objective Measures of Airway Obstruction in Children
}

\author{
Rashed A. Hasan ${ }^{*}, 1$ Walid Abuhammour ${ }^{2}$ and George Y. Zureikat ${ }^{3}$ \\ ${ }^{I}$ University of Toledo Medical School, Director of Research, Pediatric Critical Care, St. Vincent Mercy Children's \\ Hospital, Toledo, Ohio, USA \\ ${ }^{2}$ Michigan State University, Hurley Medical Center, Flint, MI, USA \\ ${ }^{3}$ Michigan State University, Pediatric Critical Care and Pulmonary Medicine, Hurley Medical Center, Flint, MI, USA
}

\begin{abstract}
Objective: The purpose of this study was to describe the effects of obesity (body mass index $\geq 95^{\text {th }}$ percentile) on objective measures of airway obstruction as determined by spirometry.

Design: Prospective cross-sectional study.

Methods: Two hundred ninty six (Age: $13.6 \pm 1.5$ Years) children from two middle schools were enrolled. The standing heights and weights in bear-feet were measured, and body mass index (BMI) was calculated. Spirometry was performed according to the American Thoracic Society guidelines. The definition of reversible airway obstruction was based on the following criteria: forced expiratory volume in one second (FEV1) $<80 \%$ predicted, and FEV1/forced vital capacity $(\mathrm{FVC})>5 \%$ lower than predicted for age and sex.
\end{abstract}

Results: Two-hundred-twenty-six children (76\%) were African-American and 71 children (24\%) were white. 138 (46\%) children were obese. 36/296 (12\%) children met the criteria for reversible airway obstruction, of which 29/296 (9.7\%) were obese. Baseline $\mathrm{FEV}_{1}$ percent predicted $(88 \pm 6$ ss $84 \pm 7 \%, \mathrm{p}=0.03), \mathrm{FEV}_{1} / \mathrm{FVC}(94 \pm 6$ vs $86 \pm 8, \mathrm{p}<0.001)$, and $\mathrm{FEV}_{1}$ percent predicted following albuterol administration $(95 \pm 7$ vs $88 \pm 7 \%, \mathrm{p}=0.03)$ were all lower in children who were obese.

Conclusions: There is an association between obesity and reversible airway obstruction as demonstrated by spirometry in children.

Keywords: Asthma, children, obesity, spirometry.

\section{INTRODUCTION}

Asthma is one of the principal causes of chronic illness in children [1-4]. Obesity is another major public health concern [5-8]. The rise in the prevalence of obesity has been attributed to lifestyle changes that have resulted in decreased energy expenditure, while the increase in asthma prevalence remains unexplained [2-6]. Because the increases in asthma and obesity appear to have coincided, it has been suggested that they may be related. Results of studies on the association between obesity and asthma in children have been inconsistent and the exact nature of the relationship remains complex [9-16].

The diagnosis of asthma in most previous studies was based on either physician-diagnosed asthma or parental report of diagnosed asthma [9-17]. In order to minimize difficulties in comparison of diagnosed cases of asthma in different populations, objective measures of lung function may be necessary [17]. Furthermore, standard Body Mass Index (BMI) reference values were not available for studies on this subject that were conducted prior to $1991[15,18]$.

*Address correspondence to this author at the University of Toledo Medical School, Pediatric Critical Care, St., Vincent Mercy Children's Hospital, 2213 Cherry Street, Toledo, Ohio, OH 43608-2603, USA; Tel: 419-2514855; Fax: 419-251-3264; E-mail: rashedh48@gmail.com
The focus of this study was to describe the proportion of inner-city children who are obese (BMI $\geq 95^{\text {th }}$ percentile) and to study the effects of being obese on objective measures of reversible airway obstruction as determined by spirometry in these children.

\section{METHODS}

This study gathered information on weight, height, BMI, and the breathing status of children enrolled in two public schools in the Detroit metropolitan area, Michigan, USA. The study was conducted from March 1 to May 31, 2006. Children with recent upper or lower respiratory diseases, chest or skeletal deformities, and immunodeficiency were excluded from the study. An informed consent was obtained from the legal guardian of all children prior to enrollment into the study. An ascent was obtained when appropriate.

Clinical diagnosis of asthma was based on the history of two more episodes of wheezing that was treated with bronchodilators or a physician diagnosis of asthma. All children were measured and weighed (Health-O-meter; Continental Scale Corp, Chicago, IL, USA) in a private area to maintain confidentiality. Height was measured with the child barefoot and erect against a wall-mounted scale (AccustatStadiometer, Genentech, San Francisco, CA, USA) and recorded to the last $0.5 \mathrm{~cm}$. Children were weighed in under- 
pants, with weight recorded to the last complete $100 \mathrm{~g}$. BMI was calculated as weight in kilograms divided by squared height in meters. Weight status was defined by using ageand gender-specific BMI percentiles from the Centers for Disease Control and Prevention (CDC) National Center for Health Statistics growth charts for the United States [19, 20]. Obesity was defined as a $B M I \geq 95^{\text {th }}$ percentile for age and sex of the person $[19,20]$.

\section{Spirometry}

Spirometry (pre and post-bronchodilator) was assessed using a 12 L dry-sealed spirometer (Renaissance II, Puritann-Bennett, Carlsbad, CA, USA). All tests conformed to the criteria of the American Thoracic Society [21, 22]. The following parameters were measured: forced vital capacity (FVC), forced expiratory volume in 1 second $\left(\mathrm{FEV}_{1}\right)$, and forced expiratory flow at mid-lung volume $\left(\mathrm{FEF}_{25-75}\right)$. The ratio of $\mathrm{FEV}_{1}$ to $\mathrm{FVC}\left(\mathrm{FEV}_{1} / \mathrm{FVC}\right)$ was calculated. All values were adjusted for body temperature and barometric pressure (BTPS). Percent predicted values for $\mathrm{FVC}, \mathrm{FEV}_{1}$, and $\mathrm{FEF}_{25-75}$ were calculated from reference values based on Harvard six cities study [23]. Subjects were asked to refrain from use of asthma medications for 24 hours before testing. Prior to use of an inhaled bronchodilator, at least 5 and no more than 8 attempts were made to obtain at least three acceptable force expiratory maneuvers. Acute bronchodilatation was achieved with inhalation of 2 puffs $(50 \mu \mathrm{gm}$ each) of albuterol metered dose inhaler (ventolin ${ }^{\mathrm{TM}}$, GlaxoSmithkline, Research Triangle Park, NC) delivered via a spacer (Optichamber Advantage, Respironics, Cedar Grove, NJ). Ten minutes later, spirometry was repeated, with no more than 5 attempts to obtain three acceptable forced expiratory maneuvers. All maneuvers were done in the standing position, with the nose pinched with a nose-clip. A single observer reviewed each study for the quality of the $\mathrm{FEV}_{1}$ and FVC.

Statistical analysis: Values are presented as mean \pm SD. Chi square analysis was used for nominal data and unpaired t-tests for continuous data. Statistical significance was assumed when the $\mathrm{p}$ value was $\leq 0.05$.

\section{RESULTS}

Three-hundred-five (out of a total of 320 children invited to participate in the study [95\% participation]) were included in the study. Nine children were excluded (None of these children met the criteria for obesity) because of unacceptable quality of spirometry. Thus, the total number of participants was 296. The demographics and other characteristics of the entire study population are shown in Table 1.

Overall, 138/296 (46\%) children were obese. 36/296 (12\%) children met the criteria for reversible airway obstruction, of which 29/296 (9.7\%) were obese. Girls were more likely to be obese $(77 / 158,48 \%)$ compared to boys $(61 / 137$, $44 \%$ ), however, this did not reach statistical significance $(\mathrm{p}=0.46)$. Eighteen $(6 \%)$ children were diagnosed with asthma by a physician or had history of recurrent wheezing that was treated with bronchodialtors, but none of them had undergone spirometry in order to evaluate for evidence of reversible airway obstruction.

Based on objective measures of lung functions by spirometry, $36(12 \%)$ children met the criteria for reversible airway obstruction, of which $29(9.8 \%)$ were obese. There was no statistically significant difference between male and female and African-American and white with regard to the diagnosis of reversible airway obstruction based on spirometry.

Table 1. The Demographics and Clinical Characteristics of the Study Population

\begin{tabular}{|l|c|}
\hline Age (years, Mean \pm SD) & $13.6 \pm 1.5$ \\
\hline Gender (M/F) & $137 / 158$ \\
\hline Body Mass Index (BMI) & $28 \pm 6.4$ \\
\hline BMI percentile & $78 \pm 20$ \\
\hline Weight (in kg) & $73 \pm 21$ \\
\hline Height (in cm) & $148 \pm 20$ \\
\hline Ethnic group (n, \%) & \\
African-American & $226(74 \%)$ \\
White & $79(26 \%)$ \\
\hline
\end{tabular}

There was not a statistically significant difference between the obese and non-obese children with regard to clinical diagnosis of asthma without spirometry $(p=0.412)$. Table 2 presents a comparison of obese and non-obese children with regard to spirometry parameters. Baseline $\mathrm{FEV}_{1}$, $\mathrm{FEV}_{1} / \mathrm{FVC}$ and $\mathrm{FEV}_{1}$ following administration of albuterol were all lower in children who were obese compared to nonobese children. Three children with a physician diagnosis of asthma reported use of albuterol metered dose inhaler (MDI) in the past week. None of these children met the criteria for reversible airway obstruction based on spirometry. Five children with a physician diagnosis of asthma reported use of albuterol MDI in the past month. Two of these children met the criteria for reversible airway obstruction based on spirometry. However, overall there was not a statistically significance association between use of albuterol MDI and a diagnosis of reversible airway obstruction by spirometry.

Table 2. Comparison of Obese (Body Mass Index $\geq 95^{\text {th }}$ Percentile) and Non-Obese Children (Body Mass Index $<5^{\text {th }}$ Percentile) with Regard to Asthma Symptoms and Spirometry Parameters

\begin{tabular}{|l|c|c|c|}
\hline \multicolumn{1}{|c|}{ Symptom/Variable } & $\begin{array}{c}\text { BMI* }^{*} \mathbf{9 5}^{\text {th }} \\
\text { Percentile } \\
\mathbf{n}=\mathbf{1 3 8}\end{array}$ & $\begin{array}{c}\mathbf{B M I}^{*}<\mathbf{9 5} \\
\text { Percentile } \\
\mathbf{n}=157\end{array}$ & $\mathbf{p}$ \\
\hline \hline $\begin{array}{l}* * * \mathrm{FEV}_{1}(\mathrm{~L}) \text { percentage of } \\
\text { predicted at baseline }\end{array}$ & $83 \pm 7$ & $87 \pm 6$ & 0.03 \\
\hline $\begin{array}{l}\mathrm{FEV}_{1} / \mathrm{FVC}^{* * * *}(\%) \\
\text { baseline }\end{array}$ & $87 \pm 8$ & $93 \pm 6$ & $<0.001$ \\
\hline $\begin{array}{l}\mathrm{FEV}_{1}(\mathrm{~L}) \text { percentage of } \\
\text { predicted after albuterol }\end{array}$ & $89 \pm 7$ & $94 \pm 7$ & 0.03 \\
\hline
\end{tabular}

*BMI $=$ body mass index, ${ }^{* * *} \mathrm{FEV}_{1}=$ forced expiratory volume in the first second of exhalation, $* * * * \mathrm{FVC}=$ forced vital capacity.

\section{DISCUSSION}

This study demonstrates the very high prevalence of obesity among inner-city children. This study also demonstrates that inner-city children who are overweight are more likely 
to have spirometric measures of reversible airway obstruction. These associations are consistent with those observed previously [11-14, 24].

Thirty-six (12\%) children met the definition of reversible airway obstruction based on objective measures of lung functions by spirometry. This is consistent with the national estimate of $11.3 \%$ for children $0-16$ years of age reported by the National Health and Nutrition Examination Survey III [16]. There was not a statistically significant difference between the African-American and white in the proportion of children who met the criteria for reversible airway obstruction based on spirometry. This is consistent with previous reports that have suggested that the higher prevalence of asthma among black children is not due to race or to low income per se, and that all children living in inner-city are at an increased risk for asthma [25].

Asthma and obesity are both common chronic conditions [1-6]. Studies on the association between asthma and obesity in children have produced conflicting results [9-16]. Definition of asthma is a concern in most previous studies, which relied on asthma questionnaires and/or a clinical diagnosis of asthma made by a physician without objective measures of lung functions [9-16]. A clinical diagnosis of asthma is dependent on the patient's perception of symptoms, in terms of frequency and severity, access to health care and the physician's diagnostic habits in the locale [17]. These factors can lead to variations in the diagnosis of asthma. Our study has some advantages in comparison to other studies on the relationship between overweight and reversible airway obstruction in children [10-16]. A strict definition of asthma based on objective measures of lung function is more likely to strengthen the association between asthma and overweight.

Children who are obese are more likely to develop asthma $[12,26]$.

Obesity is characterized by low-grade systemic inflammation with increased levels of inflammatory mediator, and acute phase proteins, including leptin, interleukin 6, tumor necrosis factor-[alpha], and $\mathrm{C}$ reactive protein. It is thought that obesity may upregulate airway inflammation, resulting in asthma [24].

However, it is also possible that reduced energy expenditure due to low levels of physical activity in children with asthma may predispose to overweight and obesity $[27,28]$. It has been demonstrated that caloric intake is similar in children with or without asthma, but children with asthma are less active than those without asthma [27]. Resting energy expenditure, which makes up the largest contribution to total energy expenditure, is greater in children with asthma when compared to children without asthma [27]. These data suggest that increases in overweight and obesity in children with asthma may be related to decreases in physical activity. Obesity may be associated with changes in airway mechanics that predispose to respiratory symptoms without airway inflammation. Excess weight compressing the chest wall, fatty infiltrate of the chest wall, and an increase in blood volume have been proposed as mechanisms for the airway obstruction associated with obesity [28].

Overweight and obese children have a greater degree and severity of bronchospasm with exercise compared to nonobese counterparts, and this phenomenon is related to the amount of subcutaneous fat [29-31]. Changes in lung volumes, as may occur with obesity, can increase airway responsiveness in individuals without asthma, and chest wall loading associated with overweight and obesity may mechanically alter airways and increase airway reactivity [28, 32, 33].

The aversion of children with asthma to exercise could lead to a reduction in physical activity and energy expenditure and development of obesity $[29,30]$. In addition to the influence of asthma and reduced activity levels in the development of overweight/obesity, these disorders may affect bronchial hyperactivity in children without asthma. However, it is important to emphasize that there are medications that children may use in preparation for exercise, including mast cell stabilizers and $\beta$-agonists [29]. When asthma is under control even children who have moderate to severe asthma can enjoy life with few physical limitations [29]. Children who have poor asthma control are more likely to experience respiratory symptoms during exercise [29, 30]. Limitations of access to health care and other health care disparities may contribute to poor asthma control in innercity children $[2,3]$.

Physicians should be aware of the relationship between asthma and overweight in inner-city children and adolescents. Initiation of preventive measures, including dietary and activity measures are critical for children who are at risk. It is the physician's responsibility to promote physical activity as part of a healthy lifestyle [34]. This is particularly true for children at risk, which include children with obese parents, or obese older siblings, and children who begin to show large increases in BMI for their age [28]. Children with comorbid asthma and obesity should receive treatment for their obesity, including a gradual increase in vigorous physical activity in order to avoid sedentary lifestyle and to increase their exercise tolerance. It is critical not to allow asthma to lead to other chronic medical conditions such as overweight and obesity, which can carry into adulthood with their own associated complications $[28,29]$. It may also be helpful to consider lifestyle modifications that involve the entire family and which can be incorporated into the family's daily routine [35]. This recommendation may be particularly important for inner-city families where optimal health care services may not be readily available [36]. This represents an important opportunity to improve the quality of lives of many of these children.

\section{LIMITATIONS}

This study has a number of limitations. It includes a small number of inner-city children studied at two secondary schools in the Midwestern part of the U.S. Participation was voluntary based the willingness of children and their parents to consent for enrollment into the study. This may introduce selection bias into the results of the study. A more critical issue is the measurement of overweight in children and adolescents. Overweight and obesity are generally understood as an increase in body weight resulting from excessive body fat. BMI is an indirect measurement of body fat, and has been used in epidemiological studies in children [6-9, 12, 21]. However, it has been suggested that BMI does not take into account the proportion of muscle mass and body frame [31]. A child who is physically active may have a high BMI but an 
acceptable level of body fat. Some studies have shown that BMI may be a poor indicator of adiposity in individual children [31]. BMI is also sex-dependent in that females have higher fat mass values than males, and BMI exhibits variations among ethnic groups [35]. BMI values that are equivalent may represent different levels of adiposity for different age, gender, and ethnic subpopulation. Furthermore, the definition of obesity has not been consistent in previous studies [9-16]. Some studies have used the $85^{\text {th }}$ percentile to define obesity, while others used a BMI $>95^{\text {th }}$ percentile to define obesity [9-16]. This may explain some of the discrepancy between the results of studies on the association between obesity and asthma in children [9-16]. The sum of triceps and subscapular skin fold thickness (sum of skin folds) is another measure of obesity that has been used to evaluate the association between asthma and obesity in children [13]. However, Figueroa-Munoz, et al. found that BMI was more consistently associated with asthma than the sum of skin folds in children 4-11 years of age [13]. We selected BMI instead of sum of skin folds, because BMI may be a better measure for assessing the association between overweight and asthma in children, and because caliper measurements are somewhat less repeatable than weight and height measurements. However, we recognize that better measurements of overweight and obesity in children are highly desirable.

Another difficulty is related to the definition of reversible airway obstruction. Even when a single definition is accepted, there are no agreed rules about how to make a diagnosis of reversible airway obstruction in an individual child. From a clinical standpoint, a diagnosis of reversible airway obstruction is made based on the history, physical examination and respiratory function tests, often over a period of time. The variability of the condition means that evidence of it may or may not be present on the day, or at the time the child is assessed.

\section{ABBREVIATIONS}

$$
\begin{array}{ll}
\mathrm{BMI}= & \text { Body mass index } \\
\mathrm{FEF}_{25-75}= & \text { Forced Expiratory Flow at 25-75\% of } \\
& \text { Expiratory Flow } \\
\mathrm{FEV}_{1}= & \text { Forced Expiratory Flow in one Second } \\
\mathrm{FVC}= & \text { Forced Expiratory Flow }
\end{array}
$$

\section{REFERENCES}

[1] Chinn S. Concurrent trends in asthma and obesity. Thorax 2005; 60: 3-4.

[2] Weiss S, Shore S. Obesity and asthma: directions for research. Am J Respir Crit Care Med 2004; 169: 963-8.

[3] Yeatts K, Davis KJ, Sotir M, Herget C, Shy C. Who Gets Diagnosed With Asthma? Frequent Wheeze Among Adolescents With and Without a Diagnosis of Asthma. Pediatrics 2003; 111: 104654.

[4] Evans D, Mellins R, Lobach K, et al. Improving care for minority children with asthma: professional education in public heath clinics. Pediatrics 1997; 99: 157-64.

[5] Ford E, Mannino D. Time trends in obesity among people with asthma: findings from three national surveys. J Asthma 2005; 42: 91-95.

[6] Story RE. Asthma and Obesity in Children. Curr Opin Pediatr 2007; 19: 680-84.

[7] Hill JO, Melanson EL. Overview of determinants of overweight and obesity: current evidence and research issues. Med Sci Sports Exerc 1999; 31: S515-21.
[8] Must A, Jacques PF, Dallal GE, Bajema CJ, Deitz WH. Long-term morbidity and mortality of overweight adolescents: a follow-up of the Harvard growth study of 1922 to 1935. N Engl J Med 1992; 327: $1350-55$.

[9] To T, Vydykhan TN, Dell S, Tassoudji M, Jarris JK. Is obesity associated with asthma in young children? J Pediatr 2004; 144: $162-68$.

[10] Schwartz J, Gold D, Dockery DW, Weiss ST, Speizer FE. Predictors of asthma and persistent wheeze in a national sample of children in the United States: association with social class, perinatal events, and race. Am Rev Respir Dis 1990; 142: 555-62.

[11] Luder E, Melnik Ta, DiMaio M. Association of being overweight with greater asthma symptoms in inner city black and Hispanic children. J Pediatr 1998; 132: 699-703.

[12] Gennuso J, Epstein LH, Paluch Ra, Cerny F. The relationship between asthma and obesity in urban minority children and adolescents. Arch Pediatr Adolesc Med 1998; 152: 1197-200.

[13] Figueroa-Munoz JI, Chinn S, Rona RJ. Association between obesity and asthma in 4-11 year old children in the UK. Thorax 2001; 56: 133-37.

[14] Von Kries R, Hermann M, Grunert VP, von Mutius E. Is obesity a risk factor for childhood asthma? Allergy 2001; 56: 318-22.

[15] Brenner JS, Kelly CS, Wenger AD, Brich SM, Morrow AL. Asthma and obesity in adolescents: is there an association? J Asthma 2001; 38: 509-15.

[16] Von Mutius E, Schwartz J, Neas LM, Dockery D, Weiss ST. Relation of body mass index to asthma and atopy in children: the National Health and Nutrition Examination Study III. Thorax 2001; 56: 835-38.

[17] National Asthma Education and Prevention Program. Expert Pannel Report 2: guidelines for the diagnosis and management of asthma, NIH Publication 97-4051; National Heart, Lung, and Blood Institute, National Institute of Health: Bethesda, MD 1997.

[18] Kaplan BA, Brush G, Mascie-Taylor CGN. The relationship of childhood asthma and wheezy bronchitis with height, weight and body mass index. Hum Biol 1987; 59: 921-31.

[19] "Healthy Weight: Assessing Your Weight: BMI: About BMI for Children and Teens". Available at: http://www.cdc.gov/nccdphp/ dnpa/healthyweight/assessing/bmi/childrens_BMI/about_childrens _BMI.htm. [Accessed Nov 22, 2008].

[20] Pupillo J. Healthy protocols. AAP News 2007; 28(8): 1-2 available at: www.aapnews. Org [Accessed Sept 2, 2007].

[21] Barlow SE, Dietz WH. Obesity evaluation and treatment: Expert Committee recommendations: the Maternal and Child Health Bureau, Health Resources and Services Administration and the Department of Health and Human Services. Pediatrics 1998; 102 (3). Available at: www.pediatrics.org/cgi/content/full/102/3/e29

[22] American Thoracic Society. Standardization of spirometry, 1994 updates. Am J Respir Crit Care Med 1995; 152: 1107-36

[23] Wang X, Dockery DW, Wypi D, Fay ME, Ferris BG. Pulomonary function between 6 and 18 years of age. Pediatr Pulmonol 1993; 15: 75-88.

[24] Shore SA, Johnston RA. Obesity and asthma. Pharmacol Ther 2006; 110: 83-102.

[25] Aligne A, Auinger P, Byrd RS, Weitzman M. Risk Factors for Pediatric Asthma. Contribution of Poverty, Race, and Urban Residence. Am J Respir Crit Care Med 2000; 162: 873-77.

[26] Troiano RP, Flegal KM, Kuczmarski RJ, Campbell SM, Johnson CL. Overweight prevalence and trends for children and adolescents: The National Health and Nutrition Examination Surveys, 1963 to 1991. Arch Pediatr Adolesc Med 1995; 149: 1085-91.

[27] Zeitlin SR, Bond S, Wootton W, Gregson RK, Radford M. Increased resting energy expenditure in childhood asthma: does this contribute towards growth failure? Arch Dis Child 1992; 67: 136669.

[28] Beuther DA, Weiss ST, Sutherland ER. Obesity and asthma. Am J Respir Crit Care Med 2006; 174: 112-19.

[29] Jang AS, Lee JH, Park SW, et al. Severe airway hyperresponsiveness in school-aged boys with a high body mass index. Korean J Intern Med 2006; 21: 10-14.

[30] Ulger Z, Demir E, Tanac R, et al. The effect of childhood obesity on respiratory function tests and airway hyperresponsiveness. Turk J Pediatr 2006; 48: 43-50.

[31] Kaplan TA, Montana E. Exercise-induced bronchospasm in nonasthmatic obese children. Clin Pediatr 1993; 32: 220-25. 
[32] Regnard J, Baudrillard P, Salah B, Xuan ATD, Cabanes L, Lockhart A. Inflation of antishock trousers increases bronchial response to methacholine in healthy subjects. J Appl Physiol 1990; 68: 152833.

[33] Ding DJ, Martin JG, Macklem PT. Effects of lung volume on maximal methacholine-induced bronchoconstriction in normal humans. J Appl Physiol 1987; 62; 1324-30.
[34] Satcher D. Physical activity and Health: A Report of the Surgeon General Executive Summary. Bethesda, MD: US Dept of Health and Human Services 1996.

[35] Dietz Wh, Gormaker SL. Do we fatten our children at the television set? Obesity and television viewing in children and adolescents. Pediatrics 1985; 75: 807-12.

[36] Ellis KJ, Abrams SA, Wong WW. Monitoring childhood obesity: assessment of the weight/height index. Am J Epidemiol 1999; 159: $939-46$.

Received: December 9, 2008

(C) Hasan et al.; Licensee Bentham Open.

This is an open access article licensed under the terms of the Creative Commons Attribution Non-Commercial License (http://creativecommons.org/licenses/by$\mathrm{nc} / 3.0 /$ ) which permits unrestricted, non-commercial use, distribution and reproduction in any medium, provided the work is properly cited. 